\title{
Anterior hyperlordotic cages: early experience and radiographic results
}

\author{
Philip A. Saville, MBChB, Abhijeet B. Kadam, MD, Harvey E. Smith, MD, and Vincent Arlet, MD \\ Department of Orthopaedic Surgery, University of Pennsylvania, Pennsylvania Hospital, Philadelphia, Pennsylvania
}

OBJECTIVE The aim of this study was to evaluate the segmental correction obtained from $20^{\circ}$ and $30^{\circ}$ hyperlordotic cages (HLCs) used for anterior lumbar interbody fusion in staged anterior and posterior fusion in adults with degenerative spinal pathology and/or spinal deformities.

METHODS The authors report a retrospective case series of $69 \mathrm{HLCs}$ in 41 patients with adult degenerative spine disease and/or deformities who underwent staged anterior, followed by posterior, instrumentation and fusion. There were 29 females and 12 males with a mean age of 55 years (range 23-76 years). The average follow-up was 10 months (range 2-28 months). Radiographic measurements of segmental lordosis and standard sagittal parameters were obtained on pre- and postoperative radiographs. Implant subsidence was measured at the final postoperative follow-up.

RESULTS For $30^{\circ} \mathrm{HLCs}$, the mean segmental lordosis achieved was $29^{\circ}$ (range $26^{\circ}-34^{\circ}$ ), but in the presence of spondylolisthesis this was reduced to $19^{\circ}$ (range $\left.12^{\circ}-21^{\circ}\right)(p<0.01)$. For $20^{\circ} \mathrm{HLCs}$, the mean segmental lordosis achieved was $19^{\circ}$ (range $\left.16^{\circ}-22^{\circ}\right)$. The overall mean lumbar lordosis increased from $39^{\circ}$ to $59^{\circ}(p<0.01)$. The mean sagittal vertical axis (SVA) reduced from $113 \mathrm{~mm}$ (range $38-320 \mathrm{~mm}$ ) to $43 \mathrm{~mm}$ (range -13 to $112 \mathrm{~mm}$ ). Six cages (9\%) displayed a loss of segmental lordosis during follow-up. The mean loss of segmental lordosis was $4.5^{\circ}\left(\right.$ range $\left.3^{\circ}-10^{\circ}\right)$. A total complication rate of $20 \%$ with a $4.1 \%$ transient neurological complication rate was observed. The mean blood loss per patient was $240 \mathrm{ml}$ (range 50-900 ml).

CONCLUSIONS HLCs provide a reliable and stable degree of segmental lordosis correction. A $30^{\circ} \mathrm{HLC}$ will produce correction of a similar magnitude to a pedicle subtraction osteotomy, but with a lower complication rate and less blood loss.

http://thejns.org/doi/abs/10.3171/2016.4.SPINE151206

KEY WORDS adult deformity; sagittal imbalance; hyperlordotic cages; ALIF; anterior lumbar interbody fusion; degenerative; technique

$\mathrm{W}$ HEN correcting complex thoracolumbar deformities, the restoration of lumbar lordosis to within $9^{\circ}$ of pelvic incidence and achieving a sagittal balance within $5 \mathrm{~cm}$ of neutral are associated with improved outcomes following spinal surgery..$^{1,4,9,11}$ Recently, it has also been suggested that outcomes are improved if the majority of the lumbar lordosis comes from the lower lumbar segments; this has helped to better define sagittal balance. ${ }^{10,15}$
Over the past 15 years or so, the correction of sagittal imbalance and restoration of lumbar lordosis in complex thoracolumbar deformities have primarily used posterior osteotomies. These osteotomies are predominantly the Smith-Petersen osteotomy (SPO) and the pedicle subtraction osteotomy (PSO). The SPO is believed to produce approximately $10^{\circ}$ of lordosis per level but requires a compliant disc space to act as a hinge. The PSO can be expected to produce approximately $30^{\circ}$ of lordosis per level, but this

ABBREVIATIONS ALIF = anterior lumbar interbody fusion; $\mathrm{ALL}=$ anterior longitudinal ligament; $\mathrm{HLC}=$ hyperlordotic cage; $\mathrm{PEEK}=$ polyetheretherketone; $\mathrm{PLL}=$ posterior longitudinal ligament; $\mathrm{PSO}=$ pedicle subtraction osteotomy; $\mathrm{SPO}=$ Smith-Petersen osteotomy; SVA = sagittal vertical axis.

SUBMITTED October 9, 2015. ACCEPTED April 27, 2016.

INCLUDE WHEN CITING Published online July 8, 2016; DOI: 10.3171/2016.4.SPINE151206. 
can be difficult to determine intraoperatively, and results can vary significantly between institutions and even between surgeons. ${ }^{2,5}$ PSOs are also associated with a very high overall complication rate up to $58 \%$, including up to an $11 \%$ neurological complication rate, significant blood loss of more than 1.1 L per osteotomy, and pseudarthrosis. $2,5-7$

The lateral transpsoas approach has also gained popularity over the past 10 years due to its less invasive nature and the ability to correct the coronal plane. Its ability to correct the sagittal plane, however, has not been well established. Recently, release of the anterior longitudinal ligament (ALL) has been advocated to facilitate lordosis. ${ }^{8,13,14}$ However, releasing the ALL from a transpsoas approach has inherent vascular risks. Even with ALL division, the correction obtained remains relatively modest. Reports published with $20^{\circ}$ or $30^{\circ}$ hyperlordotic cages (HLCs) inserted laterally show an increase in segmental lordosis of only $9.6^{\circ}$ or $11.5^{\circ}$, respectively. ${ }^{13}$ The ability to recreate lordosis from the extreme lateral interbody fusion also is limited to the region of L1-4. This is in contrast to the concept of anatomical distribution of lumbar lordosis, which dictates that $60 \%$ to $80 \%$ of the lordosis be distributed between L-4 and S-1.,15

The senior author has had extensive experience with anterior-based correction of adult spinal deformities. Before the advent of hyperlordotic cages, it was his practice to shape femoral ring allograft into a wedge to maximize lordosis correction. The availability of hyperlordotic spacers has facilitated this technique and obviates the need to customize the shape of the anterior spacers.

We hypothesize that anterior-based correction has the following advantages: 1) Complete release of the ALL will allow for maximal lordosis correction. 2) Cages designed to create lordosis may have a mechanical advantage if inserted anteriorly. Because of their wedge-shaped design, it should be easier to insert the thin, narrower end first. Insertion will create a progressive distraction of endplates to facilitate further insertion, possibly allowing correction closer to the designed amount of lordosis. 3) Predictable correction would enable the surgeon to avoid PSOs and the complications associated with posterior 3-column osteotomies. 4) This correction provides the ability to create significant lordosis at lower disc levels than the classically described L-3 PSO. 5) Predictable restoration of lordosis would allow better preoperative planning of correction.

\section{Methods}

\section{Patient Population}

Internal review board approval was obtained to conduct a retrospective review of consecutive adult patients with adult degenerative spine diseases and/or spinal deformities who underwent ALIF with a hyperlordotic cages as part of a staged anterior and posterior fusion.

Inclusion criteria were age older than 18 years and ALIF with one or more hyperlordotic cages. Exclusion criteria were inadequate pre- or postoperative imaging and previous posterior osteotomies or fusion at the planned level. For the purposes of this study, we defined hyperlordotic cages as implants designed to create $20^{\circ}$ or more of segmental lordosis. We used implants from 2 manufacturers: Brigade polyetheretherketone (PEEK) cages (NuVasive Inc.) and Cougar carbon fiber reinforced polymer cages (DePuy Synthes Spine Inc.).

\section{Surgical Technique}

All patients underwent ALIF as the first stage of staged anterior/posterior fusion. An anterior retroperitoneal approach was used for ALIF between L-4 and S-1 and an anterolateral prepsoas approach for fusion above L-4. All approaches were performed with the assistance of an access surgeon. The borders of the disc space were clearly identified, and the ALL was divided into 2 flaps in a wide horizontal H-shaped configuration. The disc was then incised and separated from the inferior and superior endplates using Cobb elevators and rongeurs. Distraction of the disc space and obtainment of the desired lordosis were achieved using the following stepwise approach: 1) Complete release of the ALL and extensive discectomy up to the posterior longitudinal ligament (PLL) was performed, with release of the PLL if necessary. 2) The patient's lumbosacral junction was positioned at the level of the hinge of the table. Relying on the jackknife capability of the operating table, the table was "jackknifed" into further lordosis during the discectomy. 3) Parallel distraction and also opening up of the disc space were achieved using large footprint paddle distractors. If such distractors did not achieve sufficient distraction, a small paddle distractor, as typically found in a transforaminal lumbar interbody fusion instrumentation tray, was inserted between the blades of the large distracters and rotated $180^{\circ}$ to "crack" open the PLL and further open up the disc space.

Once the disc space was decompressed, the hyperlordotic cage was packed with osteoconductive material (Osteocel Plus, NuVasive Inc.) soaked in bone marrow aspirate, and was inserted. Once seated, the implant was secured with screws into the endplates. Locking screws were placed through the cage, or cortical screws with a washer were placed into the inferior endplate adjacent to the cage, depending on manufacturer's design. As posterior instrumentation was planned, screws were only placed into one endplate to allow for further correction and possible SPO posteriorly. Screw fixation was found to be necessary, as the natural tendency of these hyperlordotic spacers is to extrude. Anteroposterior and lateral radiographs were then obtained to check the desired positioning of the cage and determine whether we had good endplate-to-endplate contact or a parallel distraction, which would require posterior osteotomies to generate the desired lordosis.

The choice of the cages to be inserted was determined preoperatively to restore lumbar lordosis to match the pelvic incidence and correct the sagittal vertical axis (SVA), when appropriate. Posterior instrumentation and posterior lateral fusion were performed 0-4 days after the anterior procedure. Spinal levels instrumented in the posterior fusion were dependent on the pathology being addressed.

\section{Radiographic Analysis}

Digital standard upright lateral radiographs were used to measure preoperative and postoperative sagittal param- 
TABLE 1. Breakdown of surgical indications

\begin{tabular}{lc}
\hline Surgical Indication & No. of Patients \\
\hline Degenerative conditions & 18 \\
\hline Sagittal imbalance & 12 \\
\hline Failed back syndrome & 11 \\
\hline
\end{tabular}

eters for each patient. The following measurements were obtained: lumbar lordosis, defined as the distance from the T-12 inferior endplate to the S-1 superior endplate; segmental lordosis at ALIF levels, defined as the angle between the superior and inferior endplates of a disc space; pelvic tilt; pelvic incidence; sacral slope; and SVA (for patients with sagittal imbalance). An independent nonblinded senior orthopedic resident recorded all measurements twice for consistency.

\section{Statistical Analysis}

We compared continuous variables using a nonparametric Mann-Whitney U-test. Statistical significance was set at $\mathrm{p}<0.01$.

\section{Results}

A total of 41 patients with 69 implanted cages met the inclusion criteria. There were 29 females and 12 males with a mean age of 55 years (range 23-76 years). Primary surgical indications are listed in Table 1. The mean length of radiographic follow-up was 10 months (range 2-28 months). An additional patient had inadequate imaging to assess segmental lordosis due to body habitus but was included in the calculations of complications, in view of significant postoperative complications. The ALIF levels are listed in Table 2, and the number of levels fused posteriorly in the second stage are shown in Table 3. Figures 1-3 illustrate the correction with hyperlordotic cages in a case with deformity and show the preoperative and postoperative radiographs, and CT scans, respectively. Another illustrated case (Fig. 4) is included to show the application of HLCs in spondylolisthesis.

\section{Segmental Lordosis}

A breakdown of the types of cage implanted is shown in Table 4.

\section{$30^{\circ}$ Hyperlordotic Cages}

In the absence of spondylolisthesis, $30^{\circ}$ HLCs produced a mean segmental lordosis of $29^{\circ}$ (range $26^{\circ}-34^{\circ}$ ). In the presence of spondylolisthesis, the $30^{\circ}$ HLC pro-

TABLE 2. Spinal level of ALIFs performed

\begin{tabular}{cc}
\hline ALIF Level & No. of ALIFs \\
\hline L2-3 & 3 \\
L3-4 & 12 \\
\hline L4-5 & 22 \\
\hline L5-S1 & 32 \\
\hline
\end{tabular}

TABLE 3. Number of levels of posterior fusion, in conjunction with ALIF

\begin{tabular}{cc}
\hline No. of Levels & No. of Patients \\
\hline 2 & 5 \\
\hline 3 & 7 \\
\hline 4 & 2 \\
5 & 3 \\
$\geq 6$ & 24 \\
\hline
\end{tabular}

duced a mean segmental lordosis of $19^{\circ}$ (range $12^{\circ}-21^{\circ}$ ), which is significantly different from the levels without spondylolisthesis $(\mathrm{p}<0.01)$. Only NuVasive PEEK cages were implanted, as the $30^{\circ}$ cages were only available with this manufacturer.

\section{$20^{\circ}$ Hyperlordotic Cages}

The $20^{\circ}$ HLCs produced a mean segmental lordosis of $19^{\circ}$ per cage (range $16^{\circ}-22^{\circ}$ ). Only one $20^{\circ}$ HLC was inserted at a level with spondylolisthesis, and this produced $13^{\circ}$ of segmental lordosis. There was no difference in segmental lordosis between the $20^{\circ}$ carbon fiber and the $20^{\circ}$ PEEK cages.

\section{Overall Lumbar Lordosis}

The mean lumbar lordosis increased from $39^{\circ}$ preoperatively to $59^{\circ}$ postoperatively $(\mathrm{p}<0.01)$. We defined preoperative hypolordosis as lumbar lordosis less than $42^{\circ}$ (more than 2 SDs below the parameters defined by Vialle et al. ${ }^{15}$ ). Eighteen patients met these criteria, and
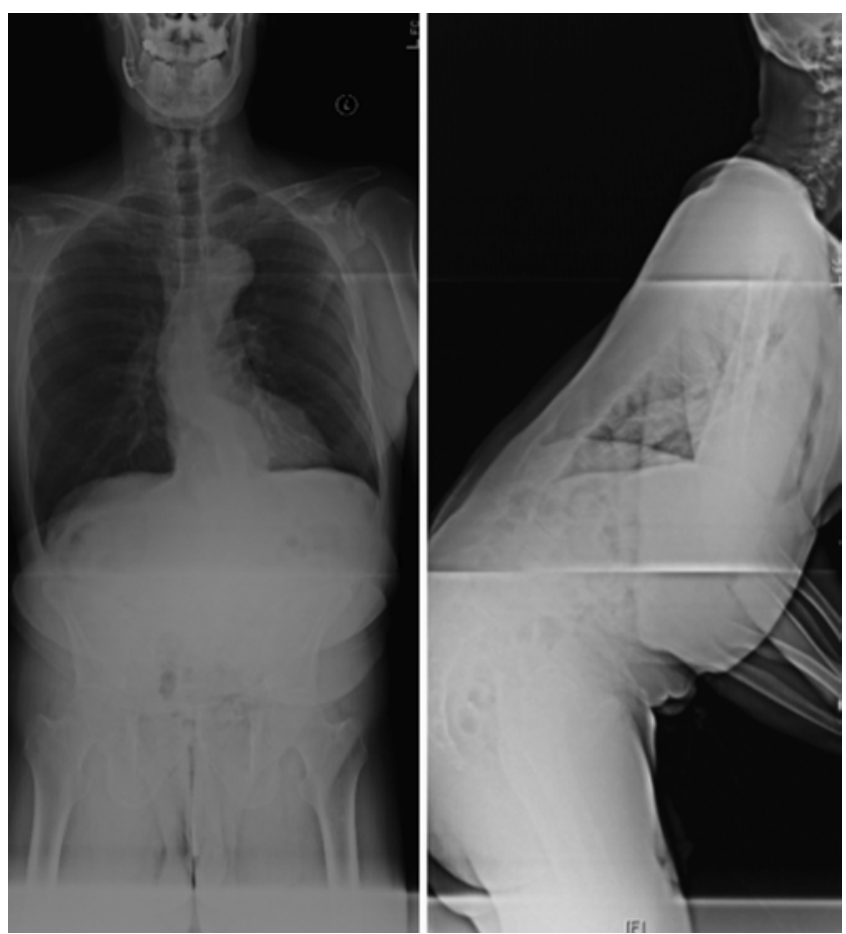

FIG. 1. Preoperative standing radiographs obtained in a patient. The patient's SVA was $51 \mathrm{~cm}$, with a $10^{\circ}$ kyphotic lumbar spine. 


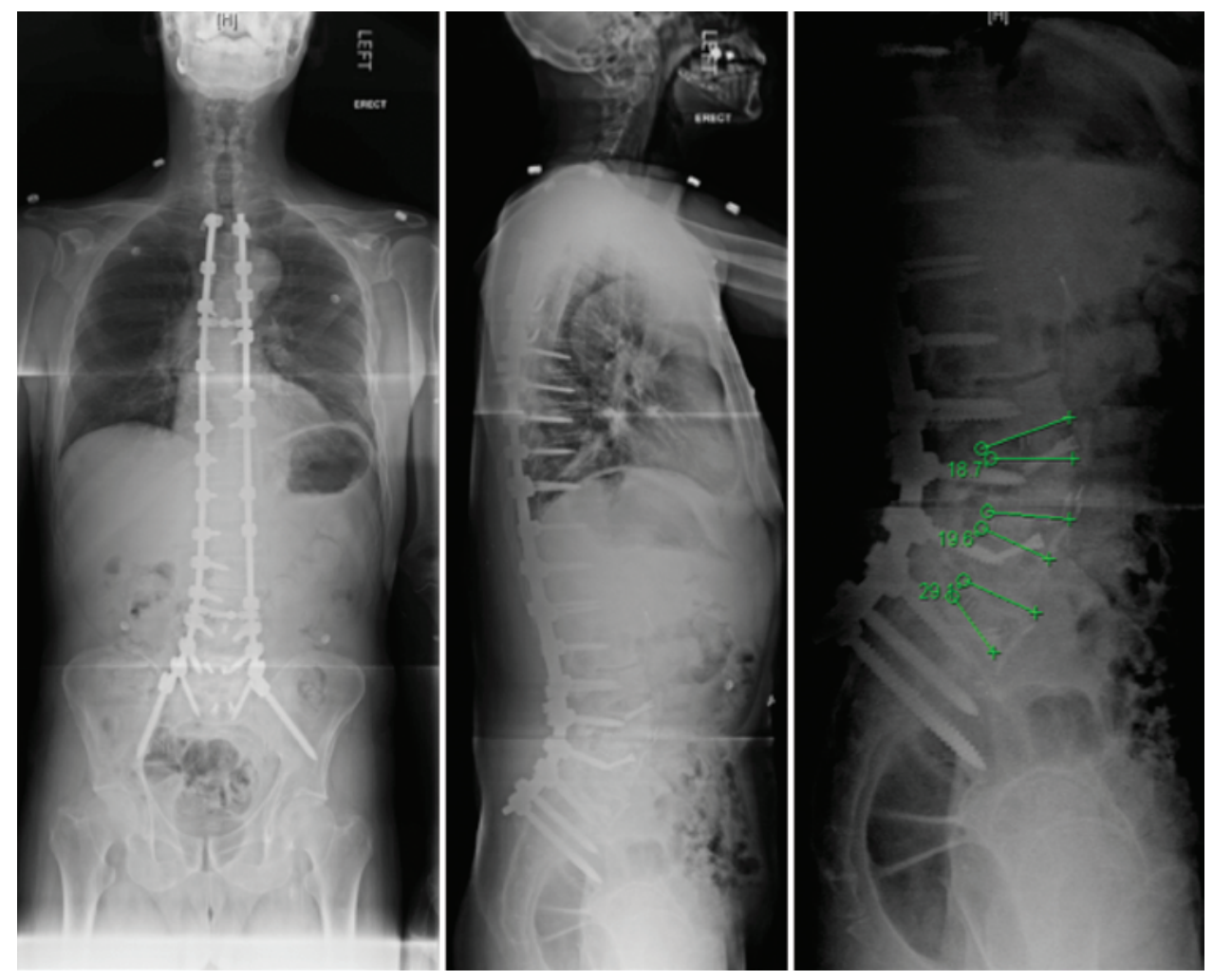

FIG. 2. Postoperative radiographs obtained in the same patient in Fig. 1, after placement of $20^{\circ} \mathrm{HLCs}$ at $\mathrm{L} 3-4$ and $L 4-5$, a $30^{\circ}$ HLC at L5-S1, and T3-pelvis PSF. The patient's SVA was restored to $2 \mathrm{~cm}$ and the LL to $65^{\circ}$. Numbers indicate segmental lordosis achieved with the HLCs at the levels of ALIFs. Figure is available in color online only.

their mean lumbar lordosis increased from $21^{\circ}$ to $55^{\circ}$ (p $<$ 0.01 ). The fact that overall lordosis did not change in line with the segmental lordosis gained was due to reciprocal changes in the segmental lordosis above the hyperlordotic cages when these segments were not fused. Thus, restoration of segmental lordosis in the lower lumbar spine was found to produce a redistribution of overall lumbar lordosis in a more anatomical fashion, causing the upper nonfused lumbar levels to fall back within the normal ranges of their intersegmental lordosis.

\section{Sagittal Balance}

The mean preoperative sagittal balance as calculated by the SVA was $113 \mathrm{~mm}$ (range 38-322 $\mathrm{mm}$ ). Postoperatively this improved to $43 \mathrm{~mm}$ (range -13 to $112 \mathrm{~mm}$ ) (p $<0.01)$.

\section{Posterior Osteotomies}

Twenty-six of 71 levels underwent SPOs during posterior surgery. The mean correction at levels with SPO was not significantly different from levels without SPO $\left(19.3^{\circ}\right.$ vs $18.8^{\circ}$ for $20^{\circ}$ cages and $29^{\circ}$ vs $28.2^{\circ}$ for $30^{\circ}$ cages). SPOs were performed in cases in which it was thought that lordosis could be maximized at levels that had more parallel rather than angular distraction of endplates and those in which complete decompression of the nerve roots at stenotic segments was necessary before rod implantation.

\section{Pelvic Parameters}

The mean preoperative pelvic incidence-lumbar lordosis mismatch of $25^{\circ}$ improved to $8^{\circ}$ postoperatively.

\section{Blood Loss}

The average blood loss per patient was $240 \mathrm{ml}$ (range $50-900 \mathrm{ml}$ ) for the anterior surgery alone. Per ALIF, this is an estimated blood loss of $140 \mathrm{ml}$.

\section{Complications}

All complications observed are listed in Table 5. The anterior complication rate was $15 \%$, and the total complication rate was $20 \%$. We observed 3 neurological complications $(4.1 \%)$. The first 2 were transient root weakness following posterior instrumentation. The third was from an adjacent-level disc prolapse that occurred 3 months following initial surgery. The patient underwent hemilaminectomy and disc fragment excision, and recovered function. There was 1 death at 3 months postoperatively caused by hemorrhage into a metastatic brain lesion, unrelated to the surgery, but yet undiagnosed at the time of surgery.

\section{Loss of Correction}

We defined loss of correction as loss of greater than $2^{\circ}$ of segmental lordosis. A total of 6 cages (9\%) displayed loss of segmental lordosis during follow-up. One of these was following a traumatic event, resulting in an axial load. 


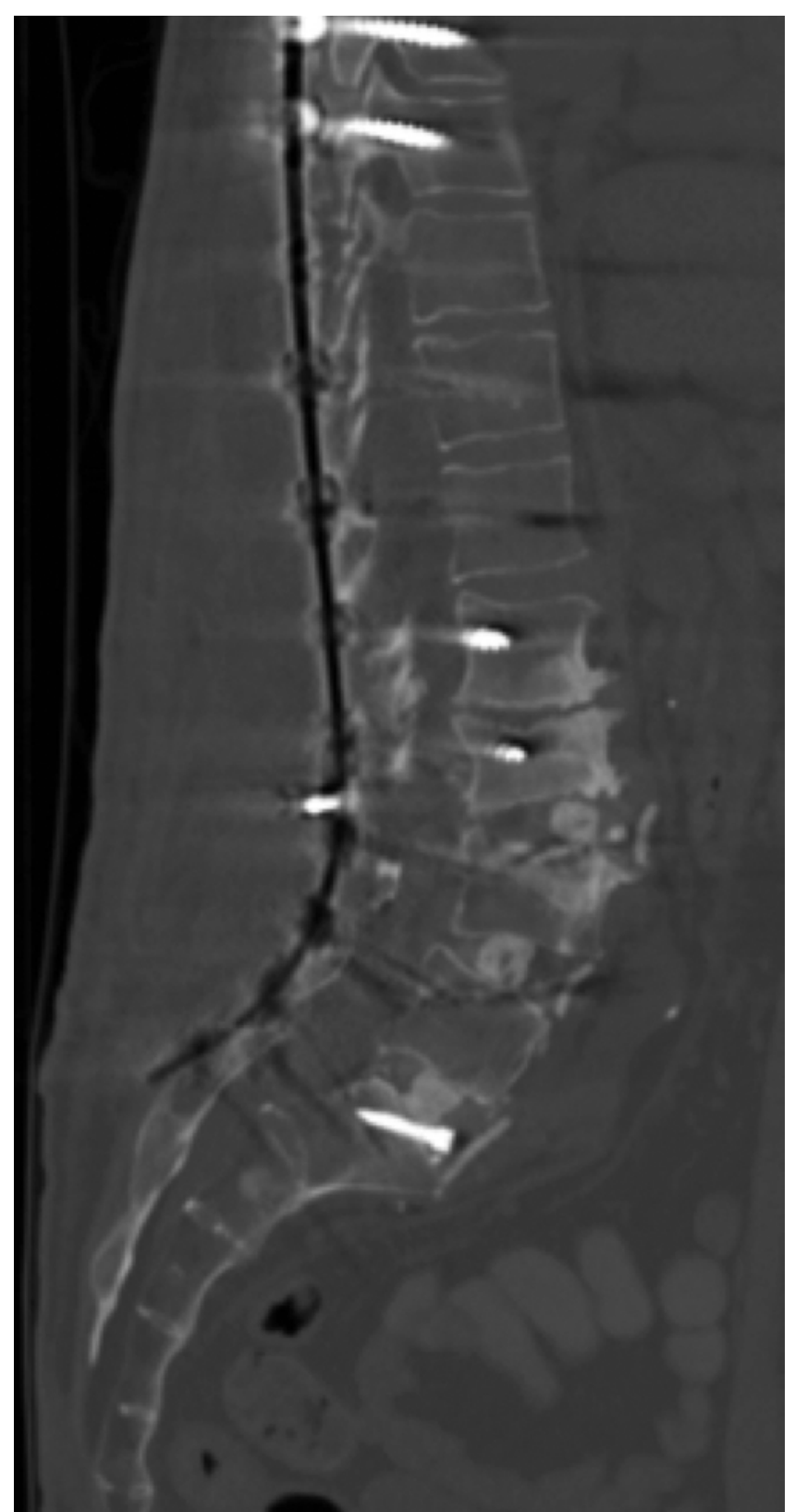

FIG. 3. Postoperative CT obtained in the same patient in Figs. 1 and 2 , showing the position of the cages and osteoconductive material. Total lumbar lordosis is $65^{\circ}$.

The mean loss of segmental lordosis among this group was $4.5^{\circ}$ (range $3^{\circ}-10^{\circ}$ ).

We observed 4 episodes of proximal junction kyphosis $(10 \%)$. Proximal extension of posterior fusion construct was performed in 3 of these cases.

\section{Discussion}

Overall, we found predictable and reproducible amounts of correction with both $20^{\circ}$ and $30^{\circ}$ HLCs. If there is no significant spondylolisthesis at the level, a $30^{\circ}$ cage will produce around $29^{\circ}$ of segmental lordosis. This would appear to be dependent on intact endplates; how-
TABLE 4. Breakdown of cages implanted

\begin{tabular}{lc}
\hline \multicolumn{1}{c}{ Cage } & No. of Cages \\
\hline $30^{\circ} \mathrm{HLC}$ & \\
\hline At level w/o spondylolisthesis & 20 \\
\hline At level w/ spondylolisthesis & 7 \\
\hline Total & 27 \\
\hline $20^{\circ} \mathrm{HLC}$ & 41 \\
\hline At level w/o spondylolisthesis & 1 \\
\hline At level w/ spondylolisthesis & 42 \\
\hline Total
\end{tabular}

ever, as evidenced by the reduced correction in one of our cases, which required an osteotomy to take down a prior fusion mass. This level of correction is comparable to results published for PSOs. ${ }^{2,7,12}$ When a spondylolisthesis is present, the segmental lordosis is significantly less at around $19^{\circ}$. The $20^{\circ}$ HLCs provided $19^{\circ}$ of segmental lordosis. In our series, only one $20^{\circ} \mathrm{HLC}$ was used in the presence of spondylolisthesis, but similar to the $30^{\circ}$ cages, this produced significantly less segmental lordosis than predicted.

The difference between the correction in spondylolisthesis and other cases can be attributed to 3 possible explanations: 1) Anterior slippage of the superior vertebra leads to concavity and convexity of the superior and inferior endplates, respectively, resulting in a domeshaped inferior endplate. This altered anatomy creates a mismatch between the cage profile and endplate. 2) When the L- 5 body was deeply situated in the pelvis we had to perform a small osteotomy of the inferior endplate of L-5 or the superior endplate of $\mathrm{S}-1$, to be able to reach the disc at L5-S1. 3) In some cases with isthmic spondylolisthesis, we observed that the insertion of HLCs can induce a parallel distraction instead of the lordotic distraction desired.

Figure 5 provides an illustration of one of the possible mechanisms for reduced correction in spondylolisthesis, as mentioned above. In all but 3 cases, cages with the preplanned amount of lordosis were implanted. The deviations from the plan all occurred with $30^{\circ}$ cages, as we were unable to attain the greater amount of distraction required for the implantation of these cages.

The amount of segmental lordosis obtained in this series is closer to the theoretical amount of lordosis available with the machined implants compared with studies reporting cages inserted from a lateral approach., ${ }^{8,14}$ This may be due to complete release of the ALL from the anterior approach and the mechanical advantage obtained from inserting a wedge with the narrower and thinner end first.

The degree of segmental lordosis obtained appears to be stable over this short time period, with only $9 \%$ displaying a fairly modest loss of lordosis $\left(4.5^{\circ}\right)$. Further follow-up is needed to determine stability over time.

As evidenced by the correction obtained in hypolordotic patients, the HLCs provide a powerful tool to correct flat back deformities. The mean correction of lumbar lordosis from $21^{\circ}$ to $55^{\circ}$ displays lordosis restoration to well 




FIG. 4. Preoperative $(\mathbf{A})$ and postoperative $(\mathbf{B}$ and $\mathbf{C})$ erect radiographs of the lumbar spine. The patient's preoperative lordosis was $76^{\circ}$, with $23^{\circ}$ distributed between S-1 and L-4. A $30^{\circ} \mathrm{HLC}$ at spondylolisthetic L5-S1 produces $16^{\circ}$ segmental lordosis and a $20^{\circ} \mathrm{HLC}$ at L4-5 produces $21^{\circ}$. The overall postoperative lordosis is $84^{\circ}$, with $52^{\circ}$ distributed between S-1 and L-4. Figure is available in color online only.

within anatomical range. It is important to mention that some significantly kyphotic cases actually displayed corrections of over $70^{\circ}$, and that HLCs should not be restricted to relatively minor deformities. It is the authors' opinion that releasing the ALL, which is mandated by the anterior approach, is of significant benefit in restoring lordosis.

The vast majority of our ALIFs were carried out at L4-5 or below (77\%). As previously mentioned, that should help to create a more natural distribution of lumbar lordosis than PSOs, which are typically performed at more proximal levels and cause abrupt angular correction. A theoretical advantage of distal lordosis creation is greater SVA correction. Using simple trigonometry, a $30^{\circ}$ correction at L5-S1 produces $23 \mathrm{~cm}$ of sagittal correction, compared with only $17 \mathrm{~cm}$ if a similar correction was achieved at L-3.

Our total complication rate was $20 \%$, which compares favorably to the $58 \%$ reported by Cho et al. for PSOs. ${ }^{7}$ An anterior-only complication rate of $15 \%$ was seen. Most of these complications are unique to the anterior approach,

\section{TABLE 5. All complications associated with the series}

\begin{tabular}{ll}
\hline \multicolumn{1}{c}{ Complications } & No. of Complications ${ }^{*}$ \\
\hline Requiring surgical intervention & \\
\hline Enterocutaneous fistula & 1 \\
\hline Lymphocele undergoing fenestration & 2 \\
\hline Retroperitoneal collection & 1 \\
\hline Adjacent disc prolapse & 1 \\
\hline Not requiring surgical intervention & 2 \\
\hline Transient neurological deficit & 1 \\
\hline Seroma & 1 \\
\hline Retroperitoneal collection & 1 \\
\hline Death, not related to surgery
\end{tabular}

* Includes the patient excluded from the study but included in the complications calculations. such as enterocutaneous fistulas and retroperitoneal collections. Given that the approaches were performed by experienced general surgeons, it may be assumed that some of these risks are inherent to anterior-based surgeries.

The mean blood loss of $240 \mathrm{ml}$ per patient, or $140 \mathrm{ml}$ per ALIF, compares favorably to values reported from PSOs of around 1.1 L per level. ${ }^{2}$

The limitations of our study include a very heterogeneous case mix for the study. A significant number of patients underwent complex spinal corrections, but other patients underwent relatively simple procedures. That said, the amount of lordosis produced by each cage was consistent between groups. Ten-month radiographic follow-up provides good short-term data, and we assume that most loss of correction would occur during this time, before fusion occurs. Longer follow-up is needed to confirm this.

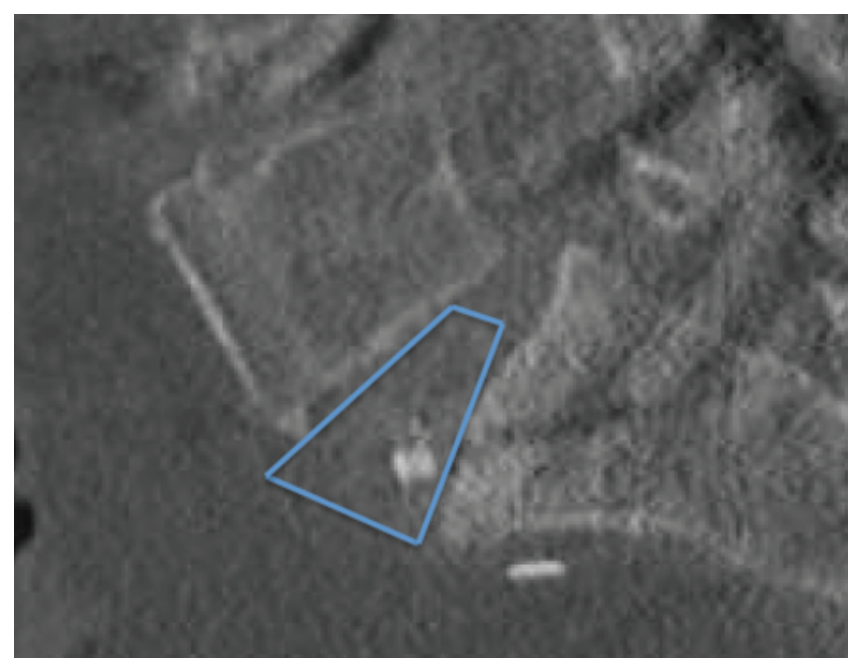

FIG. 5. CT scan showing a $30^{\circ}$ cage resting on the dome-shaped S-1 endplate in a patient with spondylolisthesis, resulting in reduced lordotic correction. The cage is highlighted in blue for clarity. Figure is available in color online only. 
Our study also does not report on fusion outcomes for HLCs, as alignment correction and not fusion was the primary parameter of interest in our study. Another limitation is that this is a single-surgeon series. The lead author has significant experience with the anterior approach, and there may be a learning curve in the technique for spine surgeons that is not appreciated in this paper.

\section{Conclusions}

Our study demonstrates that the anterior insertion of HLCs is a predictable and reproducible method to correct segmental lordosis and therefore sagittal alignment and/ or balance in complex deformities. The ability of producing predictable lordosis from anterior implants opens the possibility of accurately planning correction to match the patient's pelvic incidence and recreate the lumbopelvic parameters. The large amount of correction obtained from a $30^{\circ}$ implant also makes it possible to ensure that most of the correction is achieved in the lower lumbar segments, thus more closely recreating the natural anatomical distribution of lumbar lordosis.

\section{References}

1. Aebi M: The adult scoliosis. Eur Spine J 14:925-948, 2005

2. Barrey C, Perrin G, Michel F, Vital JM, Obeid I: Pedicle subtraction osteotomy in the lumbar spine: indications, technical aspects, results and complications. Eur J Orthop Surg Traumatol 24 (Suppl 1):S21-S30, 2014

3. Bernhardt M, Bridwell KH: Segmental analysis of the sagittal plane alignment of the normal thoracic and lumbar spines and thoracolumbar junction. Spine (Phila Pa 1976) 14:717721, 1989

4. Booth KC, Bridwell KH, Lenke LG, Baldus CR, Blanke KM: Complications and predictive factors for the successful treatment of flatback deformity (fixed sagittal imbalance). Spine (Phila Pa 1976) 24:1712-1720, 1999

5. Bridwell KH: Decision making regarding Smith-Petersen vs. pedicle subtraction osteotomy vs. vertebral column resection for spinal deformity. Spine (Phila Pa 1976) 31 (19 Suppl):S171-S178, 2006

6. Buchowski JM, Bridwell KH, Lenke LG, Kuhns CA, Lehman RA Jr, Kim YJ, et al: Neurologic complications of lumbar pedicle subtraction osteotomy: a 10-year assessment. Spine (Phila Pa 1976) 32:2245-2252, 2007

7. Cho KJ, Bridwell KH, Lenke LG, Berra A, Baldus C: Comparison of Smith-Petersen versus pedicle subtraction osteotomy for the correction of fixed sagittal imbalance. Spine (Phila Pa 1976) 30:2030-2038, 2005

8. Deukmedjian AR, Dakwar E, Ahmadian A, Smith DA, Uribe JS: Early outcomes of minimally invasive anterior longitudinal ligament release for correction of sagittal imbalance in patients with adult spinal deformity. ScientificWorldJournal 2012:789698, 2012

9. Glassman SD, Bridwell K, Dimar JR, Horton W, Berven S, Schwab F: The impact of positive sagittal balance in adult spinal deformity. Spine (Phila Pa 1976) 30:2024-2029, 2005

10. Lamartina C, Berjano P: Classification of sagittal imbalance based on spinal alignment and compensatory mechanisms. Eur Spine J 23:1177-1189, 2014

11. Le Huec JC, Cogniet A, Demezon H, Rigal J, Saddiki R, Aunoble S: Insufficient restoration of lumbar lordosis and FBI index following pedicle subtraction osteotomy is an indicator of likely mechanical complication. Eur Spine J 24 (Suppl 1):S112-S120, 2015

12. Liu H, Yang C, Zheng Z, Ding W, Wang J, Wang H, et al: Comparison of Smith-Petersen osteotomy and pedicle subtraction osteotomy for the correction of thoracolumbar kyphotic deformity in ankylosing spondylitis: a systematic review and meta-analysis. Spine (Phila Pa 1976) 40:570-579, 2015

13. Uribe JS, Harris JE, Beckman JM, Turner AWL, Mundis GM, Akbarnia BA: Finite element analysis of lordosis restoration with anterior longitudinal ligament release and lateral hyperlordotic cage placement. Eur Spine J 24 (Suppl 3):420-426, 2015

14. Uribe JS, Smith DA, Dakwar E, Baaj AA, Mundis GM, Turner AWL, et al: Lordosis restoration after anterior longitudinal ligament release and placement of lateral hyperlordotic interbody cages during the minimally invasive lateral transpsoas approach: a radiographic study in cadavers. J Neurosurg Spine 17:476-485, 2012

15. Vialle R, Levassor N, Rillardon L, Templier A, Skalli W, Guigui P: Radiographic analysis of the sagittal alignment and balance of the spine in asymptomatic subjects. J Bone Joint Surg Am 87:260-267, 2005

\section{Disclosures}

The authors report the following. Dr. Smith: consultant for DePuy Spine and Globus Spine. Dr. Arlet: consultant for NuVasive, Synthes Spine, and DePuy; and honoraria for speaking at courses for Synthes Spine.

\section{Author Contributions}

Conception and design: Arlet, Saville. Acquisition of data: Saville, Kadam. Analysis and interpretation of data: Saville, Kadam. Drafting the article: Saville. Critically revising the article: Arlet, Kadam, Smith. Reviewed submitted version of manuscript: Arlet, Kadam, Smith. Approved the final version of the manuscript on behalf of all authors: Arlet. Study supervision: Arlet.

\section{Correspondence}

Vincent Arlet, Department of Orthopaedic Surgery, Comprehensive Spine Center, 235 South 8th St., Philadelphia, PA 19107. email: vincent.arlet@uphs.upenn.edu. 